\title{
ROS-Responsive Activatable Photosensitizing Agent for Imaging and Photodynamic Therapy of Activated Macrophages
}

\author{
Hyunjin Kim¹, Youngmi Kim², In-Hoo Kim¹, Kyungtae Kim ${ }^{3 凶}$ and Yongdoo Choi ${ }^{\circledR} \bowtie$ \\ 1. Molecular Imaging \& Therapy Branch, Division of Convergence Technology, National Cancer Center, 111 Jungbalsan-ro, Ilsandong-gu, \\ Goyang, Gyeonggi-do 410-769, Republic of Korea; \\ 2. Department of Chemistry, Institute of Nanosensor and Biotechnology, Dankook University, 126 Jukjeon-dong, Yongin-si, Gyeonggi-do \\ 448-701, Republic of Korea; \\ 3. Molecular Epidemiology Branch, Division of Cancer Epidemiology and Prevention, National Cancer Center, 111 Jungbalsan-ro, Il- \\ sandong-gu, Goyang, Gyeonggi-do 410-769, Republic of Korea.
}

\begin{abstract}
$\square$ Corresponding author: Yongdoo Choi, Ph.D. Tel: +82-31-920-2512 E-mail: ydchoi@ncc.re.kr Or Kyungtae Kim, Ph.D. Tel: +82-31-920-2557 E-mail: bioktkim@ncc.re.kr.

(c) Ivyspring International Publisher. This is an open-access article distributed under the terms of the Creative Commons License (http:/ / creativecommons.org/ licenses/by-nc-nd/3.0/). Reproduction is permitted for personal, noncommercial use, provided that the article is in whole, unmodified, and properly cited.
\end{abstract}

Received: 2013.07.05; Accepted: 2013.09.25; Published: 2013.12.01

\begin{abstract}
The optical properties of macrophage-targeted theranostic nanoparticles (MacTNP) prepared from a Chlorin e6 (Ce6)-hyaluronic acid (HA) conjugate can be activated by reactive oxygen species (ROS) in macrophage cells. MacTNP are nonfluorescent and nonphototoxic in their native state. However, when treated with ROS, especially peroxynitrite, they become highly fluorescent and phototoxic. In vitro cell studies show that MacTNP emit near-infrared (NIR) fluorescence inside activated macrophages. The NIR fluorescence is quenched in the extracellular environment. MacTNP are nontoxic in macrophages up to a $\mathrm{Ce} 6$ concentration of $10 \mu \mathrm{M}$ in the absence of light. However, MacTNP become phototoxic upon illumination in a light dose-dependent manner. In particular, significantly higher phototoxic effect is observed in the activated macrophage cells compared to human dermal fibroblasts and non-activated macrophages. The ROS-responsive MacTNP, with their high target-to-background ratio, may have a significant potential in selective NIR fluorescence imaging and in subsequent photodynamic therapy of atherosclerosis with minimum side effects.
\end{abstract}

Key words: Reactive oxygen species, macrophage, theranostics, activatable, photodynamic therapy.

\section{Introduction}

Rupture of atherosclerotic plaques and the associated thrombotic complications such as myocardial infarction, stroke, and limb ischemia remains the leading cause of cardiovascular-related mortality worldwide [1-3]. Macrophages, constituting up to $20 \%$ of the cells within atherosclerotic lesions, are known to play a key role both in the development of atherosclerosis and in the formation of unstable plaques vulnerable to rupture [4]. Therefore, a large number of active macrophages in plaques have been considered a biomarker for plaque instability [5] and a prime target for the imaging and therapy of atherosclerosis [6, 7]. However, it is obvious that only the plaque-associated macrophages are undesirable, while the majority of monocytes/macrophages in circulation and in healthy tissues play important roles for homeostasis and immunity. Therefore, a method to selectively detect and kill only those macrophages 
in the plaque would be desirable.

Photodynamic therapy (PDT) using a combination of chemical photosensitizers, light, and molecular oxygen has long been used to successfully treat cancers [8]. Photosensitizers are typically nontoxic to cells in the absence of light, but become highly cytotoxic when the molecules accumulated at target sites are excited by light radiation of a specific wavelength. In vivo studies have shown that PDT promotes the stabilization of atherosclerotic plaques and inhibits plaque progression by reducing the macrophage content [9-11]. Even though a number of photosensitizers were shown to accumulate preferentially in atherosclerotic plaques, the systemic administration of most photosensitizing agents leads to significant side effects (i.e., prolonged skin photosensitivity) due to nonspecific localization of the hydrophobic photosensitizers within the skin [12-15]. Therefore, various types of macrophage-targeting PDT agents and multifunctional theranostics have been tested to improve the efficacy of PDT and the selective imaging of the activated macrophages [16-20]. An ongoing challenge in imaging and atherosclerosis therapy involves the use of "activatable" PDT agents that have shown great potential against cancers [21-30]. Activatable PDT agents with controlled optical properties are nonfluorescent and nonphototoxic in their native states, but become highly fluorescent and phototoxic upon exposure to various stimuli at target sites (i.e., enzymes and low $\mathrm{pH}$ ). These activatable PDT agents were shown to be highly efficient in selectively killing target cancer cells while minimizing unwanted skin photosensitivity. Recently, we showed the first successful in vivo results demonstrating the potential utility of an enzyme-activatable PDT agent in near-infrared (NIR) fluorescence imaging and the
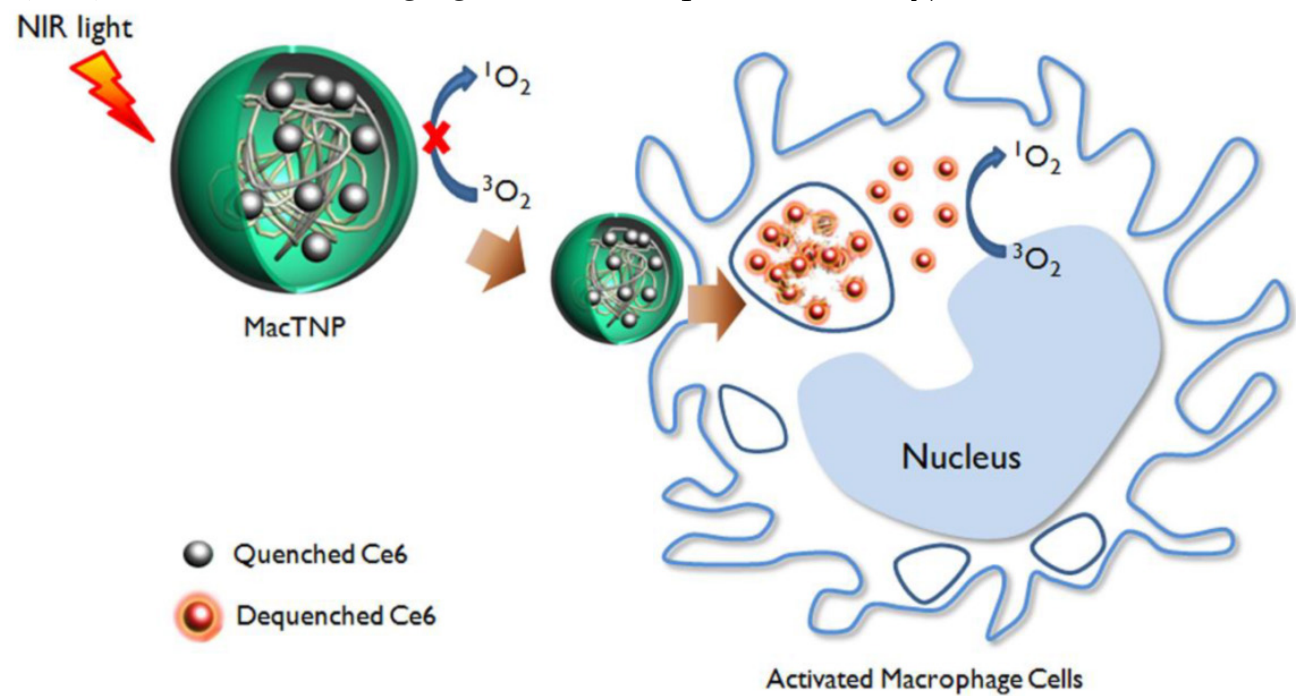

Fig I. A schematic illustration of activatable nano-photomedicine for macrophage-targeted fluorescence imaging and subsequent photodynamic therapy. Fluorescence and singlet oxygen generation of MacTNP are quenched in the native state. When ROS inside the activated macrophage cells degrade

MacTNP, the photosensitizers (Ce6s) are de-quenched and become highly fluorescent and phototoxic.

subsequent PDT of atherosclerosis [31]. The cathepsin B-activatable photodynamic theranostic agent reduced cathepsin-B activity in mouse atheromata and stabilized inflammatory plaques by selectively killing the activated macrophages in the diseased regions.

This study aims to develop a reactive oxygen species (ROS)-responsive PDT agent as a new theranostic agent for targeted imaging and therapy of the atherosclerotic lesions. It is well known that ROS generated in activated macrophages play an important immune role [32, 33]. Importantly, excess ROS are produced by activated macrophage cells in various pathogenic conditions, including atherosclerosis $[34,35]$. Therefore, we assumed that the excess ROS might represent a good target for developing macrophage-targeted "activatable" theranostics. According to previous reports, polysaccharides including hyaluronic acid could be depolymerized by ROS $[36,37]$. Therefore, we prepared macrophage-targeted theranostic nanoparticles (MacTNP) by conjugating photosensitizers to hyaluronic acid (Figure 1 and 2). We expected that fluorescence and singlet oxygen generated from the MacTNPs in the native state would be inhibited due to self-quenching effect between the conjugated photosensitizers. When MacTNPs are internalized by the activated macrophages, the excess ROS in the cells degrades the nanoparticles by cleaving the chemical bonds of hyaluronic acid. This results in photosensitizer release from the nanoparticles, which results in fluorescence emission and singlet oxygen generation. Such a ROS-responsive MacTNP may have great potential in selective NIR fluorescence imaging with high target-to-background ratio and subsequent PDT of atherosclerosis with minimized side effects (i.e., skin photosensitivity). 


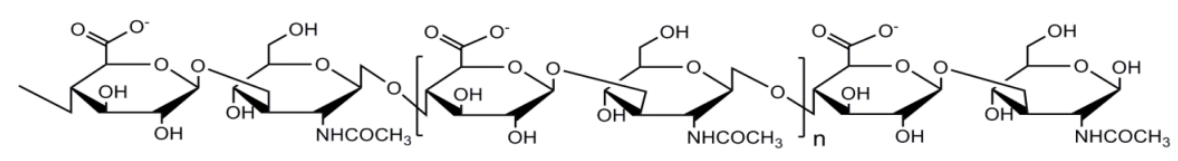

Hyaluronic acid (Mw 2I5,000)
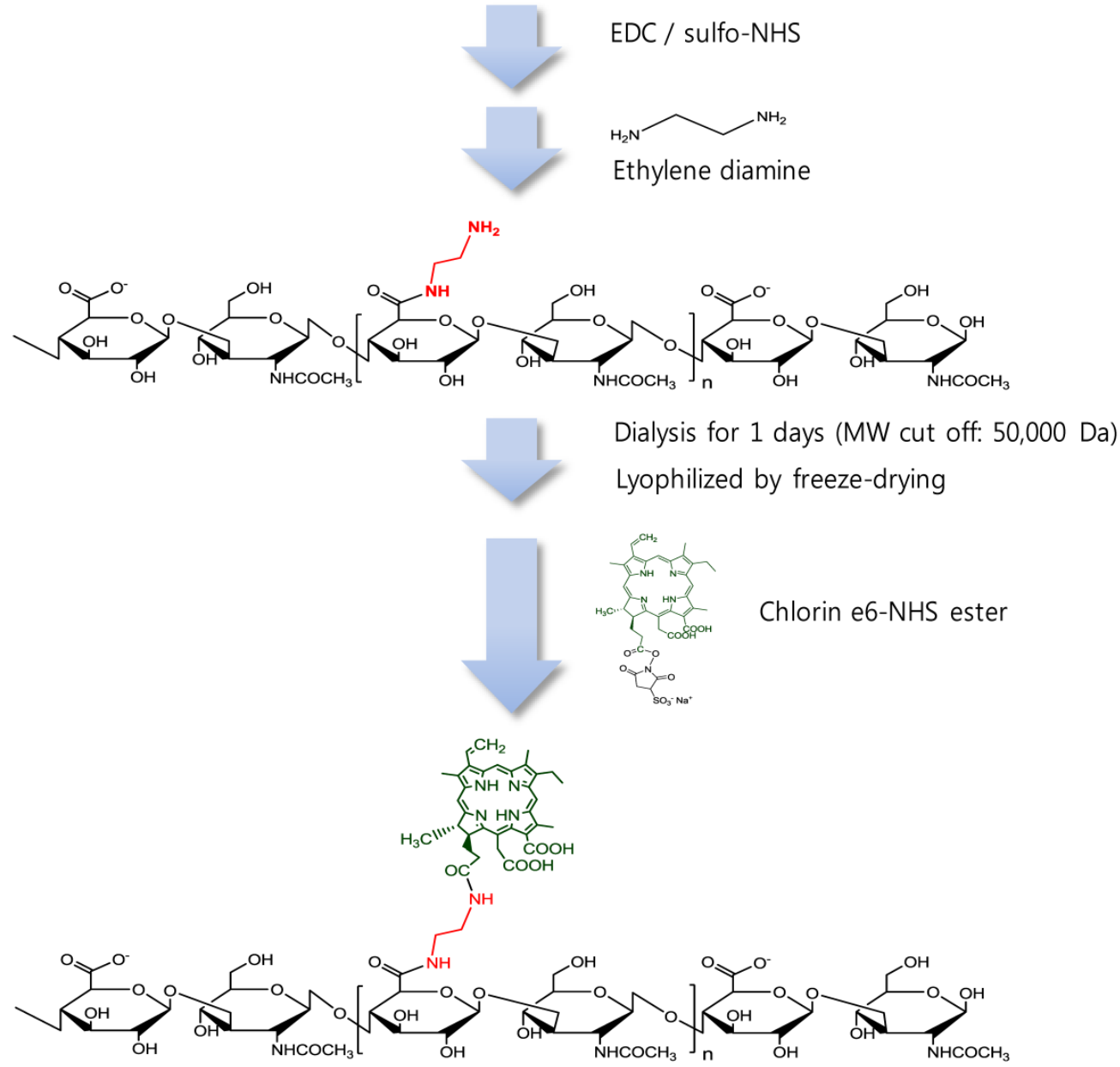

Fig 2. Synthetic production of $\mathrm{HA}-\mathrm{Ce} 6$ conjugates.

\section{Materials and Methods}

\section{Materials}

Hyaluronic acid (HA, MW 215,000 Da) was purchased from Lifecore Biomedical (Chaska, MN, USA). 1-Ethyl-3(3-dimethylaminopropyl) carbodiimide (EDC), sulfo-N-hydroxysulfosuccinimide (sulfo-NHS), ethylene diamine, and hyaluronidase (HAdase, 1,228 units/mg) were purchased from Sigma-Aldrich (MO, USA). Chlorin e6 (Ce6) and dialysis membranes (MW cut-off: 50,000 Da) were purchased from Frontier Scientific (UT, USA) and Spectrum Laboratories (CA, USA), respectively. Singlet Oxygen Sensor Green (SOSG), which is a singlet-oxygen-detecting reagent, was obtained from Invitrogen (NY, USA).

Lipopolysaccharide (LPS) and recombinant murine interferon-gamma (INF- $\gamma$ ) were purchased from
List Biological Laboratories, INC. (CA, USA) and PeroTech (NJ, USA), respectively. The Raw 264.7 macrophage cell line was obtained from the American Type Culture Collection (Rockville, MD, USA). Human dermal fibroblast (HDF) cells were kindly provided by Dr. Sang Chul Park (College of Medicine, Seoul National University, Republic of Korea). Both cell lines were maintained in Dulbecco's Modified Eagle Medium (DMEM; GIBCO ${ }^{\circledR}$, Invitrogen) supplemented with $10 \%(\mathrm{v} / \mathrm{v})$ fetal bovine serum (FBS) and $1 \%$ antibiotic-antimycotic solution in a humidified incubator at $37^{\circ} \mathrm{C}, 5 \% \mathrm{CO} 2$.

\section{Preparation of MacTNP}

MacTNP were prepared from a hyaluronic acid-chlorin e6 (HA-Ce6) conjugate (Figure 2). First, amine-functionalized HA was synthesized by conjugating ethylene diamine with the carboxylic acid component of HA using standard EDC/NHS chem- 
istry. Briefly, $200 \mathrm{mg}$ of HA was dissolved in phosphate buffer solution ( $\mathrm{pH} 7.4,10 \mathrm{mM}, 19 \mathrm{~mL}$ ); EDC (35 $\mathrm{mM}, 0.5 \mathrm{~mL})$ and sulfo-NHS $(42 \mathrm{mM}, 0.5 \mathrm{~mL})$ were sequentially added to the HA-dissolved aqueous solution. After $30 \mathrm{~min}$, ethylene diamine $(93 \mathrm{mg})$, dissolved in the phosphate buffer ( $\mathrm{pH} 7.4,10 \mathrm{mM}, 1 \mathrm{~mL})$ was added to the activated HA solution, and the reaction was allowed to proceed overnight at room temperature. The reactant was then dialyzed against deionized (DI) water and lyophilized. To conjugate the amine-functionalized HA with Ce6, the carboxylic acid of Ce6 $(50 \mathrm{mg}, 10 \mathrm{~mL})$ was activated with EDC $(21 \mathrm{mM})$ and sulfo-NHS $(28 \mathrm{mM})$ in dimethyl sulfoxide (DMSO). Aminated HA (200 mg) was dissolved in dimethylformamide (DMF): $\mathrm{H}_{2} \mathrm{O}$ cosolvent $(1: 1 \mathrm{v} / \mathrm{v}, 5$ $\mathrm{mL})$, mixed with the activated Ce6 solution, and then reacted for $18 \mathrm{~h}$ at room temperature. The resulting HA-Ce6 solution was dialyzed against phosphate buffer ( $\mathrm{pH} 7.4,10 \mathrm{mM})$ and then with DI water to remove unreacted Ce6s and the byproducts. Self-assembled HA-Ce6 nanoparticles (henceforth called MacTNP) were formed during the dialysis procedure in the aqueous solution. MacTNP was finally freeze-dried. The products obtained at each step were analyzed by proton nuclear magnetic resonance ( $\left.{ }^{1} \mathrm{H}-\mathrm{NMR}\right)$ (Supplementary Material: Figure S1).

\section{Characterization of MacTNP}

The surface charge of MacTNP was measured using a zeta potential/particle-sizer (Malvern Instrument, Malvern, UK), after dispersing the particles in DI water. The hydrodynamic size was measured after dispersing in phosphate-buffered saline (PBS; 6.7 $\mathrm{mM}, \mathrm{pH} 7.4,154 \mathrm{mM} \mathrm{NaCl})$.

For the analysis of the optical properties, MacTNP were dispersed in PBS. For comparison, free Ce6 was dissolved in Tween 20-containing PBS solution $(1 \% \mathrm{v} / \mathrm{v})$ to avoid photosensitizer aggregation in the aqueous solution. Then UV/Vis spectra of MacTNP and free Ce6 solutions were measured with an UV/Vis spectrometer (DU730, Beckman Coulter, Brea, CA) to check the aggregation of Ce6s in the nanoparticles (final concentration, $5 \mu \mathrm{M} \mathrm{Ce}$ ). The concentration of Ce6 in MacTNP and free Ce6 stock solutions was calculated by dissolving the nanoparticles in $0.1 \mathrm{M} \mathrm{NaOH} / 0.1 \%$ sodium dodecyl sulfate (SDS), and then the absorbance at $400 \mathrm{~nm}$ was measured. Ce6 is known to have a molar extinction coefficient of $1.5 \times 10^{5} \mathrm{M}^{-1} \mathrm{~cm}^{-1}$ at $400 \mathrm{~nm}$ [38]. The fluorescence spectra of MacTNP and free Ce6 (with 400 nm excitation) were obtained on a multifunctional microplate reader (Safire 2; Tecan, Männedorf, Switzerland). MacTNP and free Ce6 were maintained at a final concentration of $5 \mu \mathrm{M}$ Ce6.

The inhibitory characteristics of singlet oxygen generation (SOG) in MacTNP were evaluated by measuring the fluorescence intensity increase of SOSG during light irradiation, which was then compared with that of free Ce6. SOSG was dissolved in PBS saturated with oxygen gas containing either MacTNP or free Ce6. The final concentration of SOSG reagent was maintained at $1 \mu \mathrm{M}$. The final concentration of MacTNP and free Ce6 were 0.5 $\mu \mathrm{M}$ Ce6. SOSG fluorescence intensity $\left(\lambda_{\mathrm{ex}} 504 \mathrm{~nm}, \lambda_{\mathrm{em}} 525 \mathrm{~nm}\right.$ ) was then measured periodically, during light irradiation with a 670-nm CW laser (irradiation dose rate $50 \mathrm{~mW} / \mathrm{cm}^{2}$ ).

\section{ROS-responsive recovery of fluorescence and SOG in the MacTNP}

To examine the ROS-mediated recovery of fluorescence and SOG, MacTNP were reacted with various ROS and the fluorescence intensity and SOG were measured. ROS generators were prepared according to a previous report [37]: $50 \mu \mathrm{M} \mathrm{KO}_{2}$ for the superoxide anion $\left(\mathrm{O}_{2}{ }^{-}\right), 50 \mu \mathrm{M} \mathrm{H}_{2} \mathrm{O}_{2}$ with $5 \mu \mathrm{M}$ ferrous perchlorate for the hydroxyl radical $(\mathrm{OH}), 50 \mu \mathrm{M}$ hydrogen peroxide $\left(\mathrm{H}_{2} \mathrm{O}_{2}\right)$ with $50 \mu \mathrm{M} \mathrm{NaOCl}$ for hypochlorite $\left(\mathrm{OCl}^{-}\right)$, and $50 \mu \mathrm{M} \mathrm{H}_{2} \mathrm{O}_{2}$ with $10 \mu \mathrm{M}$ nitrite for peroxynitrite (ONOO-) [37]. MacTNP (final concentration: $0.5 \mu \mathrm{M}$ Ce6) were incubated for $2 \mathrm{~h}$ with various ROS in PBS (pH 7.4), and then the fluorescence intensity of Ce6 was measured $\left(\lambda_{\text {ex }} 400 \mathrm{~nm}, \lambda_{\mathrm{em}}\right.$ $660 \mathrm{~nm})$. Next, the samples were mixed with an oxygen-saturated PBS solution containing concentrated SOSG. The final concentration of SOSG was adjusted to $1 \mu \mathrm{M}$. The fluorescence intensities of the samples were measured before light irradiation to check if ROS in the samples could alter the fluorescence of SOSG. Finally, SOSG fluorescence changes were measured after irradiating the solutions with a $670-\mathrm{nm}$ continuous wave $(\mathrm{CW})$ laser (irradiation dose rate 50 $\mathrm{mW} / \mathrm{cm}^{2}$ ) for $120 \mathrm{~s}$. All the experiments were performed in quadruplicate.

In another set of experiments, the effect of peroxynitrite concentration on fluorescence intensity of MacTNP was tested by incubating MacTNP (equiv. Ce6 concentration of $0.5 \mu \mathrm{M}$ ) with peroxynitrite at different concentrations $(0,5,10,20,40$, and $100 \mu \mathrm{M})$ in PBS ( $\mathrm{pH} 7.4$ ) for $2 \mathrm{~h}$, and then measuring the fluorescence intensity of MacTNP ( $\lambda_{\text {ex }} 400 \mathrm{~nm}, \lambda_{\text {em }} 660$ $\mathrm{nm})$.

All the experiments were performed in quadruplicate.

\section{The effect of hyaluronidase on fluorescence recovery of MacTNP}

The effect of hyaluronidase (HAdase) on the recovery of MacTNP fluorescence was evaluated by treating MacTNP (equiv. Ce6 concentration of $1 \mu \mathrm{M}$ ) with hyaluronidase in different concentrations $(0,10$, 
$50,100$, and $500 \mathrm{U} / \mathrm{mL})$ in sodium acetate buffer (100 $\mathrm{mM}, \mathrm{pH} 4.5,100 \mathrm{mM} \mathrm{NaCl}$ ) for $1 \mathrm{~h}$. Then the samples were diluted with PBS ( $\mathrm{pH} 7.4$ ), and fluorescence intensity of Ce6 was measured ( $\lambda_{\mathrm{ex}} 400 \mathrm{~nm}, \lambda_{\mathrm{em}} 660 \mathrm{~nm}$ ). The experiments were performed in quadruplicate.

\section{Evaluation of fluorescence quenching and re- covery in activated macrophage cells: live cell fluorescence imaging}

MacTNP and free Ce6 were diluted in fresh DMEM medium supplemented with $10 \%$ FBS to obtain $1 \mu \mathrm{M}$ Ce6.

Raw 264.7 cells were plated at a density of $1 \times 10^{6}$ cells/well in a 12-well plate (BD Biosciences) and incubated for $24 \mathrm{~h}$ to allow cell attachment. The cells were activated by treatment with $1 \mu \mathrm{g} / \mathrm{mL}$ lipopolysaccharide (LPS) and $50 \mathrm{ng} / \mathrm{mL}$ interferon-gamma (INF- $\gamma$ ) for $24 \mathrm{~h}$. The cell culture medium was replaced with fresh medium containing the photosensitizers. Then, without washing the cells, NIR fluorescence images ( $\lambda_{\text {ex }} 640 \pm 15 \mathrm{~nm}, \lambda_{\text {em }} 690 \pm 25 \mathrm{~nm}$ ) of the activated macrophage cells were recorded every 15 min for $2 \mathrm{~h}$ using a Live Cell Imaging System (Axio observer Z1, 10×, NA 0.55, Carl Zeiss, Germany). All the images were acquired at the same microscope settings in order to ensure reproducibility.

\section{Intracellular uptake of MacTNP}

MacTNP were diluted in the culture medium containing $10 \%$ FBS to obtain a final Ce6 concentration of $1 \mu \mathrm{M} \mathrm{Ce} 6$. Normal HDF cells were selected as a ROS-negative control. HDF and Raw 264.7 cells were seeded in a 96-well plate at $1 \times 10^{4}$ cells/well and incubated for $24 \mathrm{~h}$ for cell attachment. Raw 264.7 cells were activated by treatment with LPS $(1 \mu \mathrm{g} / \mathrm{mL})$ and INF- $\gamma(50 \mathrm{ng} / \mathrm{mL})$ for $24 \mathrm{~h}$. For comparison, both HDF cells and nonactivated macrophage cells were incubated for $24 \mathrm{~h}$ in the absence of LPS and INF- $\gamma$. Then the existing culture medium was replaced with $100 \mu \mathrm{L}$ of fresh medium containing MacTNP. At $2 \mathrm{~h}$ post-incubation, all the cells were washed 3 times with PBS, and treated with $200 \mu \mathrm{L}$ of $0.1 \mathrm{M}$ $\mathrm{NaOH} / 0.1 \%$ SDS solution for $2 \mathrm{~h}$ for inducing both cell lysis and complete disaggregation of the self-assembled MacTNP. Finally, the Ce6 fluorescence of the cell lysates was measured on a multifunctional microplate reader $\left(\lambda_{\text {ex }} 400 \mathrm{~nm}, \lambda_{\text {em }} 660 \mathrm{~nm}\right)$. The fluorescence of MacTNP in the cell lysate was completely de-quenched by using $0.1 \mathrm{M} \mathrm{NaOH} / 0.1 \%$ SDS, thereby enabling quantitative comparison of the internalized photosensitizers in the cells. As untreated controls, HDF, non-activated and activated macrophage cells were treated with cell culture media without MacTNP for $2 \mathrm{~h}$. Then, the cells were washed 3 times with PBS, treated with $200 \mu \mathrm{L}$ of $0.1 \mathrm{M}$
$\mathrm{NaOH} / 0.1 \%$ SDS solution for $2 \mathrm{~h}$, and the Ce6 fluorescence of the cell lysates was measured $\left(\lambda_{\text {ex }} 400 \mathrm{~nm}\right.$, $\left.\lambda_{\mathrm{em}} 660 \mathrm{~nm}\right)$. All the experiments were performed in quadruplicate.

\section{Flow cytometric analysis and confocal fluo- rescence microscopy}

To check the fluorescence recovery in macrophages, fluorescence intensities of the MacTNP-treated cells were measured by fluorescence-activated cell sorting (FACS). HDF and Raw 264.7 cells were plated at $1 \times 10^{6}$ cells/well onto a 12-well plate and incubated for $24 \mathrm{~h}$ for cell attachment. Raw 264.7 cells were activated with LPS (1 $\mu \mathrm{g} / \mathrm{mL})$ and INF- $\gamma(50 \mathrm{ng} / \mathrm{mL})$ for $24 \mathrm{~h}$. For comparison, HDF and non-activated Raw 264.7 cells were incubated for $24 \mathrm{~h}$ in the absence of LPS and INF- $\gamma$. Then, the existing cell culture medium was replaced with fresh medium containing MacTNP at the equivalent concentration of $1 \mu \mathrm{M}$ Ce6. After incubation for 2 $\mathrm{h}$, the cells were washed 3 times with PBS, harvested, and their fluorescence intensities were analyzed by FACS $\left(\lambda_{\text {ex }} 633 \mathrm{~nm}, \lambda_{\text {em }} 660 \pm 20 \mathrm{~nm}\right)$.

For NIR confocal fluorescence imaging study, Raw 264.7 cells were seeded at $1 \times 10^{5}$ cells/well in a LabTek II Chambered Coverglass (Nalge Nunc International Corp.) and incubated for $24 \mathrm{~h}$ for cell attachment. Activated macrophages were obtained by treating Raw 264.7 cells with LPS $(1 \mu \mathrm{g} / \mathrm{mL})$ and INF- $\gamma(50 \mathrm{ng} / \mathrm{mL})$ for $24 \mathrm{~h}$. HDF and non-activated Raw 264.7 cells were incubated for $24 \mathrm{~h}$ in the absence of LPS and INF- $\gamma$. Then, the existing cell culture medium was replaced with fresh medium containing MacTNP (equiv. Ce6 concentration of $1 \mu \mathrm{M}$ ). After incubation for $2 \mathrm{~h}$, the cells were washed 2 times with PBS, and incubated in fresh culture medium. NIR fluorescence images $\left(\lambda_{\text {ex }} 633 \mathrm{~nm}, \lambda_{\text {em }} 700 \pm 50 \mathrm{~nm}\right)$ of the cells were acquired by confocal scanning-laser microscopy (CSLM, ZEISS LSM 510 META).

\section{Cytotoxicity testing}

Raw 264.7 macrophages were seeded in a 96-well plate at $1 \times 10^{4}$ cells/well, incubated for $24 \mathrm{~h}$ for cell attachment, and then activated with LPS and INF- $\gamma$ for $24 \mathrm{~h}$. MacTNP were diluted in cell culture medium containing $10 \%$ FBS to obtain Ce6 concentrations of 1 $\mu \mathrm{M}, 3 \mu \mathrm{M}, 6 \mu \mathrm{M}$, and $10 \mu \mathrm{M}$, respectively. The existing culture medium was replaced with $100 \mu \mathrm{L}$ of fresh medium containing MacTNP, and then the cells were further incubated for $24 \mathrm{~h}$. After the cells were washed twice, fresh cell culture medium was added. The cell viability was measured using a cell counting kit (CCK-8; Dojindo Laboratories, Mashikimachi, Kumamoto, Japan). The absorbance was measured at 450 $\mathrm{nm}$ (reference $=650 \mathrm{~nm}$ ) using a microplate reader 
(Tecan Safire 2, Switzerland). The viability of the untreated controls was taken to be $100 \%$, while the medium served as the background. Data are expressed as the mean (SD) of 4 data samples.

\section{In vitro phototoxicity testing}

Raw 264.7 macrophage cells were seeded in a 96-well plate at $1 \times 10^{4}$ cells/well, incubated for $24 \mathrm{~h}$ for cell attachment. Activated macrophages were obtained by treating Raw 264.7 cells with LPS $(1 \mu \mathrm{g} / \mathrm{mL})$ and INF- $\gamma \quad(50 \mathrm{ng} / \mathrm{mL})$ for $24 \mathrm{~h}$. HDF and non-activated Raw 264.7 cells were incubated for $24 \mathrm{~h}$ in the absence of LPS and INF- $\gamma$. Then, the existing cell culture medium was replaced with fresh medium containing MacTNP at the equivalent concentration of $1 \mu \mathrm{M}$ Ce6. After incubation for $2 \mathrm{~h}$, the cells were washed twice, fresh cell culture medium was added, and the cells were irradiated using a 670-nm CW laser at light doses of 5 and $10 \mathrm{~J} / \mathrm{cm}^{2}$ (light dose rate: 50 $\left.\mathrm{mW} / \mathrm{cm}^{2}\right)$. The cells were further incubated for $18 \mathrm{~h}$. The viability of the cells was analyzed using the CCK-8 kit. The viability of the untreated HDF and Raw 264.7 cell controls was taken to be $100 \%$, while the medium served as the background. Data are ex- pressed as the mean (SD) of 4 data samples.

\section{Results and Discussion}

\section{Characterization of MacTNP}

To synthesize HA-Ce6 conjugates, the carboxylic acids of the HA backbone were first modified with ethylene diamine and then conjugated with Ce6s using EDC/NHS chemistry (Figure 2 and Supplementary Material: Fig. S1). Based on the UV/Vis spectrum analysis, the number of conjugated Ce6s per a single HA backbone was calculated to be 91 .

As expected, the amphiphilic HA-Ce6 conjugates self-assembled into nanoparticles having hydrodynamic size and zeta potential of $103.1 \pm 38.4 \mathrm{~nm}$ and $22.6 \pm 16.5 \mathrm{mV}$, respectively, in aqueous solution (Figure 3A). The significant broadening of the Soret band region in the UV/Vis spectrum of MacTNP (Figure 3B and Supplementary Material: Fig. S2) also confirmed the aggregation of the conjugated hydrophobic Ce6 molecules in the aqueous environment, while the negative zeta potential of the MacTNP indicated that the hydrophilic HA backbones were localized at the surface of MacTNP.
A

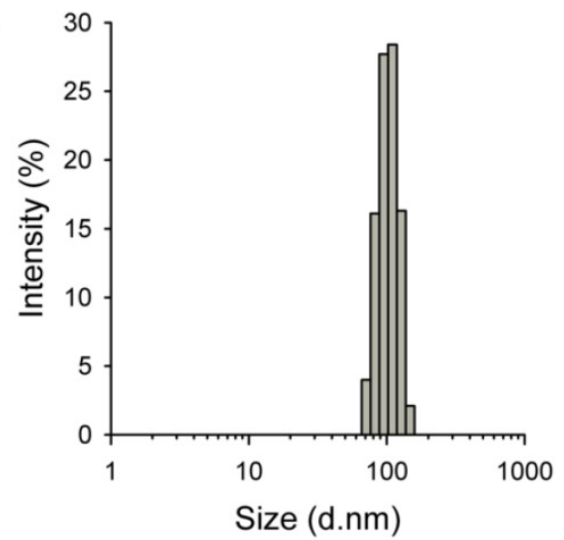

C

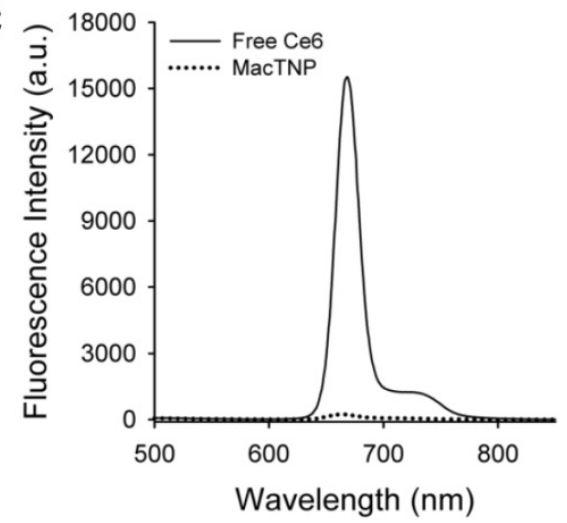

B

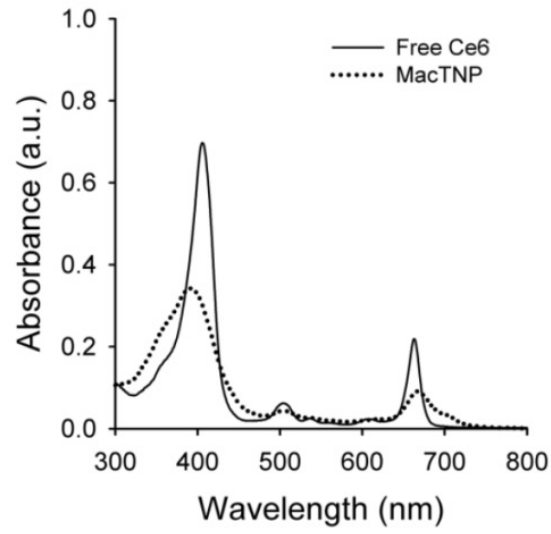

D

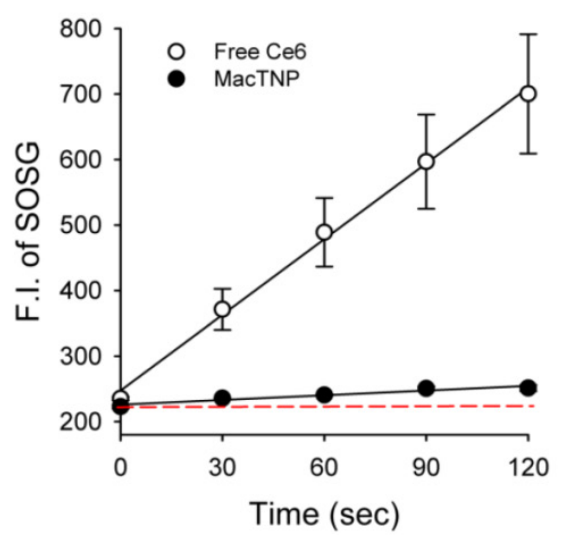

Fig 3. Characterization of MacTNP. (A) Hydrodynamic size distribution of MacTNP in PBS solution. (B) UV/Vis absorption and (C) fluorescence spectra of free Ce6 (solid line) and MacTNP (dotted line) at $5 \mu$ M Ce6. (D) Time-dependent singlet oxygen generation of free Ce6 and MacTNP during light irradiation (670-nm CW laser, light dose rate: $\left.50 \mathrm{~mW} / \mathrm{cm}^{2}\right)$. The dashed line represents the baseline SOSG fluorescence. 
A

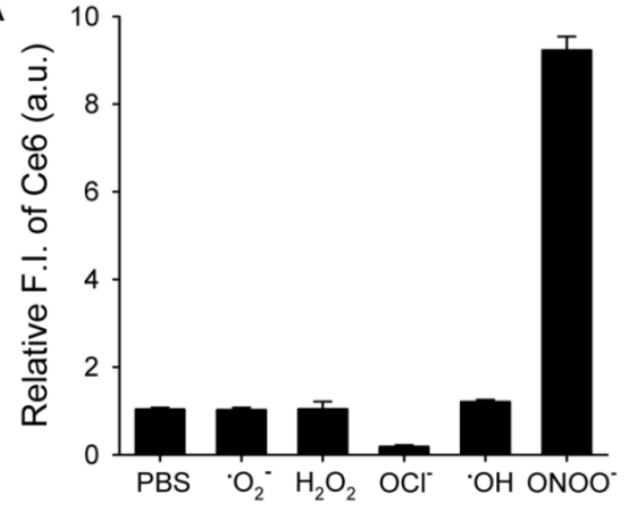

B

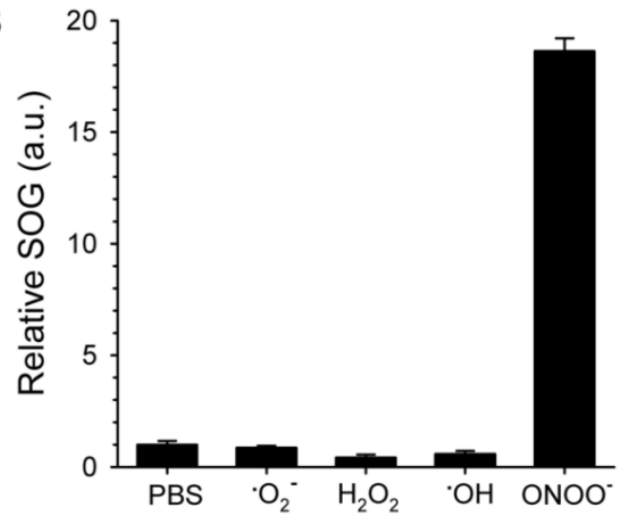

Fig 4. ROS-responsive recovery of fluorescence and SOG. MacTNPs were reacted with various ROS ( $n=4)$. Then, $(A)$ the Ce6 fluorescence in the samples was measured and compared with that of the control (i.e., PBS-treated MacTNP). (B) Relative SOG after treatment with ROS. ROS-treated samples were irradiated using a $670-\mathrm{nm} \mathrm{CW}$ laser for $120 \mathrm{~s}$, and the relative SOG was calculated by comparing the normalized SOSG fluorescence of the samples with that of the control.

As shown in Figure 3C, due to the aggregation of Ce6s in the self-assembled nanoparticles, the fluorescence of MacTNP was dramatically quenched (i.e., only $1.6 \%$ of the fluorescence intensity of free Ce6). A consistent quenching in the MacTNP production of reactive singlet oxygen was observed, where the singlet oxygen sensor green (SOSG) reagent was used as a probe to detect SOG by free Ce6 and MacTNP (Figure 3D). During the 670-nm laser irradiation, in comparison to that from free $\mathrm{Ce} 6$, a minor increase in the SOSG fluorescence emission was observed for MacTNP, indicating that MacTNP SOG was inhibited. SOG from MacTNP was 16-fold lower than that from free Ce6.

\section{ROS-responsive recovery of fluorescence and SOG in the MacTNP}

Next, we checked if ROS could act as a switch for fluorescence emission recovery and SOG by de-quenching of Ce6 by degrading MacTNP (Figure 4). Previous studies have examined the degradation of HA backbones and its mechanism [38-41]. In particular, peroxynitrite is known to induce HA fragmentation in a site-selective manner at the $N$-acetylglucosamine $\beta$ - $(1 \rightarrow 4)$ glycosidic bonds resulting in the formation of oligosaccharides differing by disaccharide units [39]. Accordingly, we expected that the degradation of MacTNP upon ROS treatment would result in the release of Ce6 and the subsequent recovery of the fluorescence intensity. When MacTNP in PBS $(0.5 \mu \mathrm{M}$ Ce6) were treated with various chemically generated ROS at $50 \mu \mathrm{M}$ for $2 \mathrm{~h}$, only peroxynitrite (ONOO-)-treated MacTNP showed 9.3-fold increase in the fluorescence intensity compared to PBS-treated MacTNP as the control (Figure 4A). The other ROS did not induce a significant recovery of MacTNP fluorescence, probably because of insufficient disintegration of the self-assembled MacTNP.
When fluorescence intensity of MacTNP incubated with peroxynitrite at different concentrations $(0$, $5,10,20,40$, and $100 \mu \mathrm{M}$ ) was measured, fluorescence recovery of MacTNP was dose-dependent on the peroxynitrite concentration (Supplementary Material: Figure S3). Particularly, there was a linear dependence $\left(r^{2}=0.959\right)$ of the fluorescence intensity on the peroxynitrite concentration in the $0-40 \mu \mathrm{M}$ range. Previous reports note that the stimulated expression of inducible nitric oxide synthase is associated with atherosclerosis, and the activity of this enzyme preferentially promotes the formation of peroxynitrite [42]. Therefore, the dose-dependent fluorescence recovery of MacTNP by peroxynitrite suggests that MacTNP may also be useful for the specific imaging of peroxynitrite levels in atherosclerotic lesions.

Before examining SOG recovery, we checked whether ROS caused any change in the fluorescence intensity of SOSG reagent. Since $\mathrm{NaOCl}$ caused the denaturation of Ce6 (Supplementary Material: Figure S4), we excluded the $\mathrm{NaOCl}$-treated samples in this experiment. As a result, it was confirmed that ROS did not affect SOSG fluorescence (Supplementary Material: Figure S5). As in the fluorescence experiment, the treatment of MacTNP with peroxynitrite induced an 18-fold increase in SOG while the other ROS produced no significant increases (Figure 4B).

\section{Effect of HAdase on the fluorescence recovery of MacTNP}

HAdase rapidly degrades HA through preferential cleavage of $\beta$ - $(1 \rightarrow 4)$ glycosidic bonds [43], similar to peroxynitrite. HAdase activity has been reported to increase in atheromatous plaques [44]. Therefore, we checked if MacTNP fluorescence could be affected by HAdase in addition to ROS (Figure 5). Interestingly, the effect of HAdase on the fluorescence intensity of MacTNP was negligible, showing only $30 \%$ increase 
in MacTNP fluorescence even upon treatment with $100 \mathrm{U} / \mathrm{mL}$ HAdase.

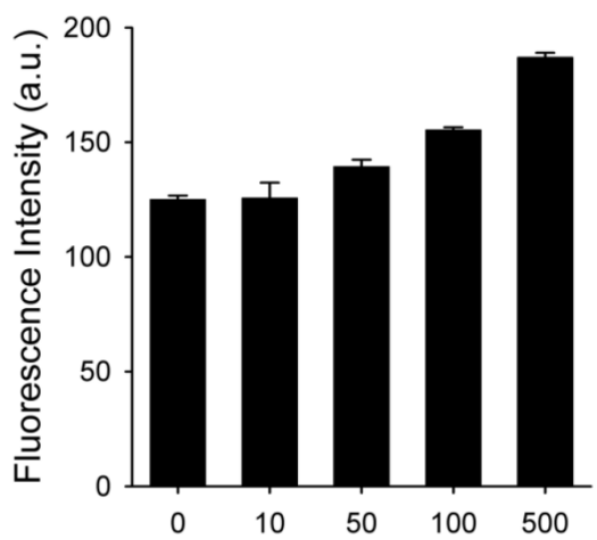

Hyaluronidase (Unit/mL)

Fig 5. Fluorescence intensity of MacTNP after treatment with different concentrations of hyaluronidase $(n=4)$.

\section{Live cell imaging of fluorescence recovery in activated macrophage cells}

In order to demonstrate the utility of MacTNP in macrophage-targeted imaging, we applied both free Ce6 and MacTNP to the activated Raw 264.7 cells (Figure 6). Since the fluorescence of MacTNP is expected to be quenched in the extracellular environment and turned on only inside the activated macrophages, the NIR fluorescence were acquired every 15 min for $2 \mathrm{~h}$ without washing the photosensitizers. As expected, only weak fluorescent signals were detected in the extracellular space surrounding the MacTNP-treated cells at $15 \mathrm{~min}$, whereas a highly intense fluorescence was continuously observed in the free Ce6-treated cells. As shown in Figure 6 (upper images), the cells became noticeably brighter with time and were strongly fluorescent after $2 \mathrm{~h}$ of incubation, indicating the fluorescence turn-on inside the cells. This result indicates that activatable MacTNP are potentially useful in the selective NIR fluorescence imaging of atherosclerotic lesions with a high target-to-background ratio in vivo.

\section{Intracellular uptake of MacTNP in normal fi- broblast and macrophage cells}

Before evaluating differences in fluorescence activation of MacTNP in normal HDF and macrophage cells, we compared the amount of MacTNP intracellular uptake in these cells. HDF, non-activated and activated Raw 264.7 cells were incubated with MacTNP at Ce 6 concentration of $1 \mu \mathrm{M}$ for $2 \mathrm{~h}$, washed 3 times with PBS, treated with $0.1 \mathrm{M} \mathrm{NaOH} / 0.1 \%$ SDS solution for inducing both cell lysis and disaggregation of the self-assembled MacTNP, and fluorescence intensities of the cell lysates were measured. Since treatment of the cells with $0.1 \mathrm{M} \mathrm{NaOH} / 0.1 \%$ SDS solution induces complete disassembly of MacTNP and subsequent de-quenching of Ce6 fluorescence, intracellular uptake of MacTNP in these cells could be compared by measuring fluorescence intensities of Ce6 in the cell lysates. Strong NIR fluorescence was measured from the MacTNP-treated cells while minor fluorescence was detected from the untreated control cells (Figure 7A). There was no statistically significant difference in fluorescence intensity between the cells, indicating that similar amount of MacTNP was internalized.

\section{Flow cytometric analysis and confocal fluo- rescence microscopy}

Recovery of Ce6 fluorescence in the activated macrophages was further evaluated by FACS analysis (Figure 7B). HDF, non-activated and activated Raw 264.7 cells were incubated with MacTNP at Ce6 concentration of $1 \mu \mathrm{M}$ for $2 \mathrm{~h}$, washed 3 times with PBS, harvested, and their fluorescence intensities analyzed by FACS. MacTNP-treated activated Raw 264.7 cells showed 3-fold greater mean fluorescence intensity than MacTNP-treated HDF cells. Also mean fluorescence intensity of the MacTNP-treated non-activated Raw 264.7 cells was only $61 \%$ of that of the MacTNP-treated activated Raw 264.7 cells. Since intracellular uptake of MacTNP was similar in these cells (Figure 7A), FACS results indicate the release of Ce6 molecules from MacTNP, with subsequent fluorescence recovery inside the activated macrophage cells. In addition, significantly higher fluorescence recovery of MacTNP was obtained in the activated macrophages compared to their non-activated counterparts. NIR fluorescence images obtained by confocal laser scanning microscopy (CLSM) also supported MacTNP fluorescence recovery within the activated Raw 264.7 cells (Figure 7C).

\section{Cytotoxicity testing}

Activated Raw 264.7 cells were treated with MacTNP for 24 h over a Ce6 concentration range of $0-10 \mu \mathrm{M}$ in order to determine Ce6 toxicity in the dark. As expected, cells treated with MacTNPs showed no cytotoxicity even at the highest Ce6 concentration (Figure 8A), confirming the excellent biocompatibility of MacTNP.

\section{In vitro phototoxicity testing}

In contrast to the dark cytotoxicity test, cell viability following treatment with MacTNP (equiv. Ce6 concentration of $1 \mu \mathrm{M}$ ) decreased in a light dose-dependent manner upon irradiation with $670-\mathrm{nm}$ CW laser (Figure 8B). In particular, $66 \%$ of the 
activated Raw 264.7 cells were dead after light irradiation $\left(10 \mathrm{~J} / \mathrm{cm}^{2}\right)$ whereas no statistically significant decrease in cell viability was observed in the HDF cells after light irradiation. As expected from the FACS analysis, PDT effect of MacTNP in the activated macrophages was significantly higher than in non-activated macrophage cells $(P<0.001)$. The order of phototoxicity observed was HDF < non-activated Raw 264.7 cells $<$ activated Raw 264.7 cells.

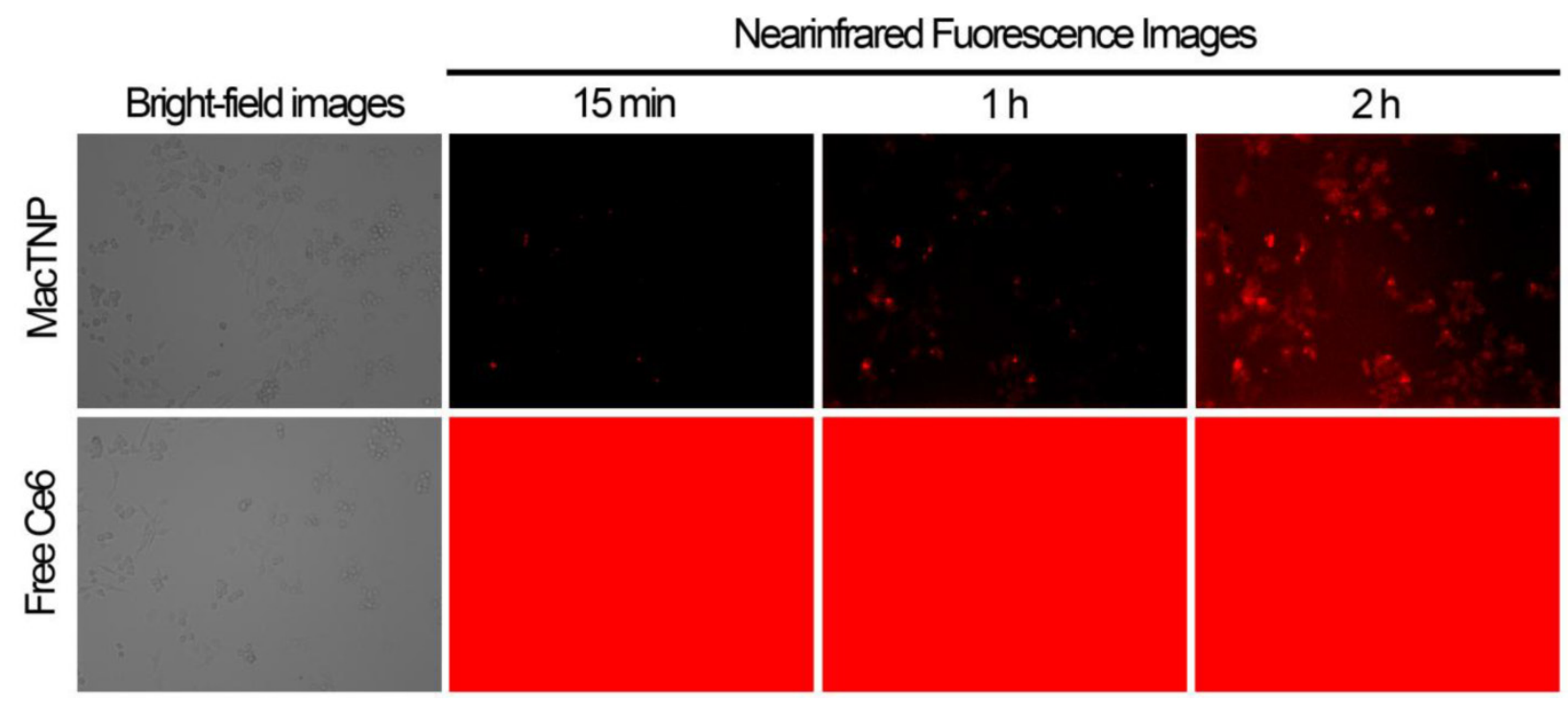

Fig 6. NIR fluorescence images obtained from live cell fluorescence microscopy. Activated macrophages were incubated with MacTNP and free Ce6 at I $\mu \mathrm{M} \mathrm{Ce}$, and then, without washing the cells, NIR fluorescence images were obtained every $15 \mathrm{~min}$ for $2 \mathrm{~h}$. The red color indicates the fluorescence signals generated from Ce6 photosensitizers $\left(\lambda_{\mathrm{ex}} 640 \pm 15 \mathrm{~nm}, \lambda_{\mathrm{em}} 690 \pm 25 \mathrm{~nm}\right)$.

A

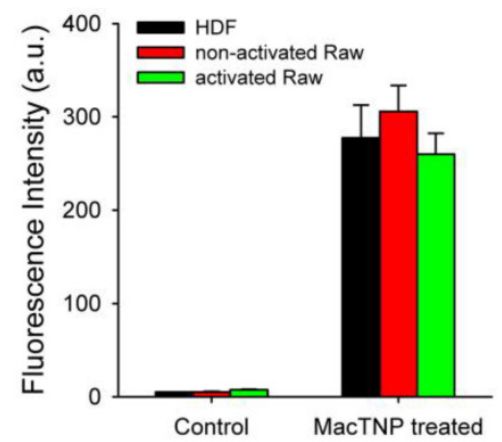

B

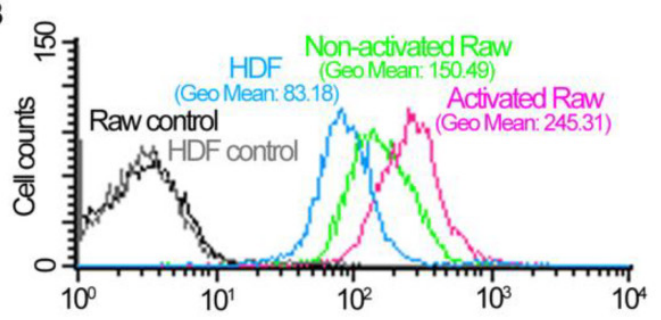

C

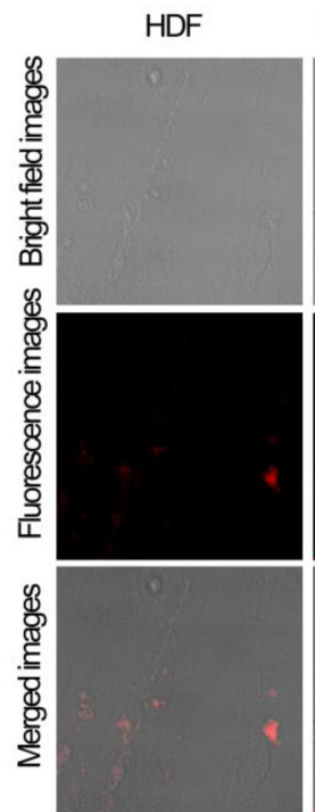

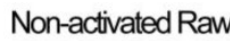
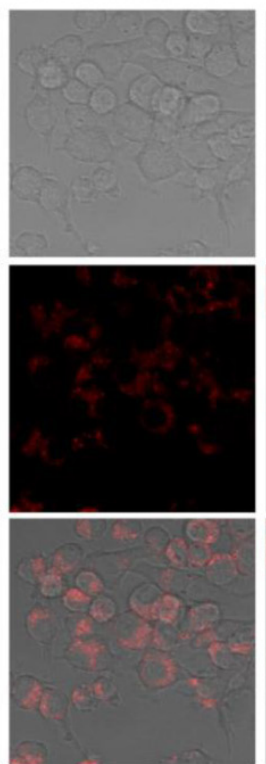

Activated Raw

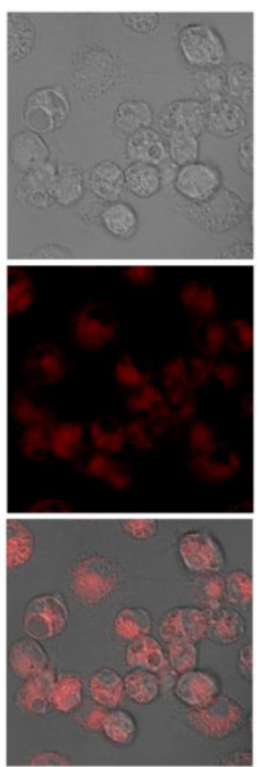

Fig 7. (A) Fluorescence intensities measured from the cell lysates $\left(\lambda_{\text {ex }} 400 \mathrm{~nm}, \lambda_{\text {em }} 660 \mathrm{~nm}\right)$. MacTNPs in the cell lysates were completely de-quenched by $0.1 \mathrm{M} \mathrm{NaOH} / 0.1 \%$ SDS solution, thereby enabling comparison of the amount of photosensitizer in the cell lysates. No significant difference in Ce6 fluorescence was observed between MacTNP-treated cells $(n=4)$. (B) Flow cytometric analysis of Ce6 fluorescence in HDF, non-activated and activated Raw 264.7 cells $\left(\lambda_{\text {ex }} 633 \mathrm{~nm}, \lambda_{\text {em }} 660 \pm 20 \mathrm{~nm}\right)$. (C) Confocal scanning fluorescence images of the MacTNP-treated HDF, non-activated and activated macrophages $\left(\lambda_{\text {ex }} 633 \mathrm{~nm}, \lambda_{\text {em }} 700 \pm 50 \mathrm{~nm}\right)$. 

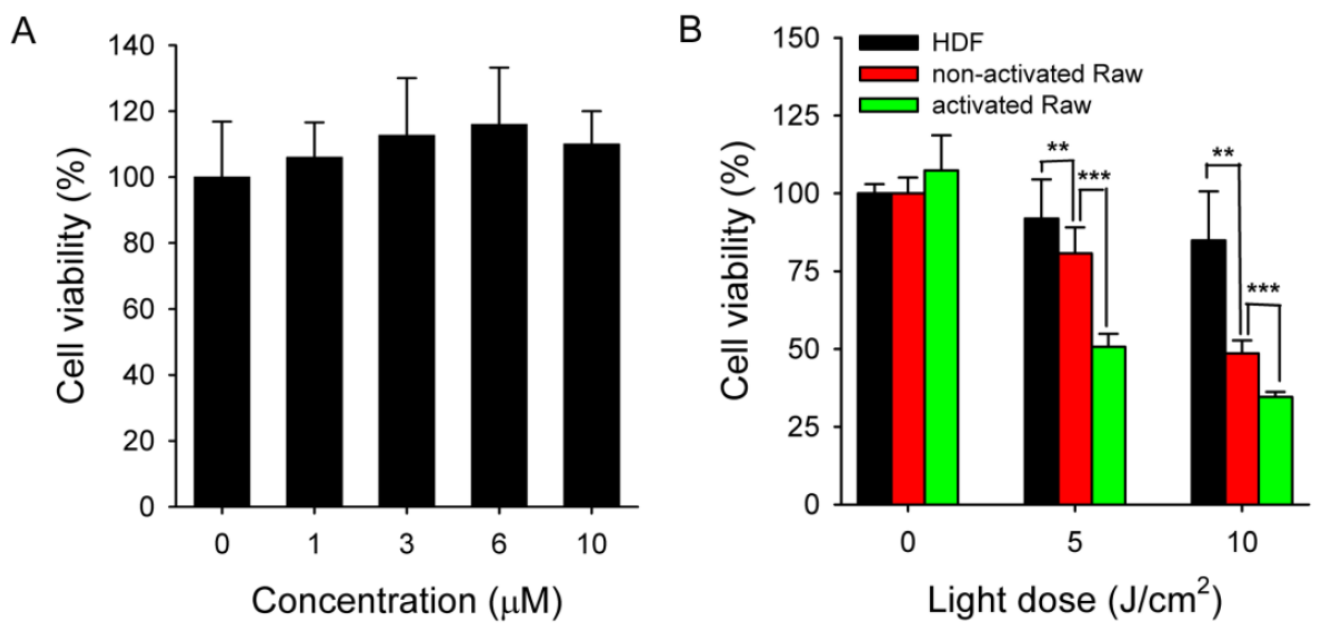

Fig 8. (A) Dark toxicity testing of MacTNP. Cells were treated with MacTNPs at various concentrations for $24 \mathrm{~h}$ and cell viability was measured without light irradiation $(n=4)$. (B) In vitro phototoxicity test $(n=4)$. Cells were treated with MacTNP at Ce6 concentration of I $\mu M$ for $2 h$, washed 2 times, and irradiated using a 670-nm CW laser at various light doses (light dose rate: $50 \mathrm{~mW} / \mathrm{cm}^{2}$ ). $* * P<0.01$, $* * * P<0.001$.

\section{Conclusions}

Biocompatible MacTNP are nonfluorescent and nonphototoxic in their native state. However, they become highly fluorescent and phototoxic upon treatment with peroxynitrite. In vitro cell studies confirm that the fluorescence emission and SOG of MacTNP are recovered inside the activated macrophages. We believe that the MacTNPs developed in this study may be potentially useful for selective NIR fluorescence imaging and PDT of atherosclerosis lesions in vivo.

\section{Supplementary Material}

Fig.S1 - Fig.S5.

http://www.thno.org/v04p0001s1.pdf

\section{Acknowledgements}

This work was supported by a National Cancer Center grant (1310160-1) and the Pioneer Research Center Program of Korea funded by the Ministry of Science, ICT \& Future Planning (2013-009119), Republic of Korea.

\section{Conflict of Interests}

The authors have declared that no competing interest exists.

\section{References}

1. Farb A, Burke AP, Tang AL Liang TY, Mannan P, Smialek J, Virmani R. Coronary plaque erosion without rupture into a lipid core: a frequent cause of coronary thrombosis in sudden coronary death. Circulation 1996; 93: 1354-63.

2. Virmani R, Kolodgie F, Burke A, Farb A, Schwartz SM. Lessons from sudden coronary death: a comprehensive morphological classification scheme for atherosclerotic lesions. Arterioscler Thromb Vasc Biol 2000; 20: 1262-75.

3. Hellings WE, Peeters W, Moll FL, Pasterkamp G. From vulnerable plaque to vulnerable patient: the search for biomarkers of plaque destabilization. Trends Cardiovasc Med 2007; 17: 162-71.

4. Cassells W, Hathorn B, David M, Krabach T, Vaughn WK, McAllister HA Bearman G, Willerson JT. Thermal detection of cellular infiltrates in living atherosclerotic plaques: possible implications for plaque rupture and thrombosis. Lancet 1996; 347: 1447-51.

5. Amirbekian V, Lipinski MJ, Briley-Saebo KC, Amirbekian S, Aguinaldo JGS, Weinreb DB, Vucic E, Frias JC, Hyafil F, Mani V, Fisher EA, Fayad ZA. Detecting and assessing macrophages in vivo to evaluate atherosclerosis noninvasively using molecular MRI. Proc Nat Acad Sci USA 2007; 104: 961-6

6. Jaffer FA, Libby P, Weissleder R. Molecular imaging of cardiovascular disease. Circulation 2007; 116: 1052-61.

7. McCarthy JR. Nanomedicine and cardiovascular disease. Curr Cardiovasc Imaging Rep 2010; 3: 42-9.

8. Dolmans DE, Dai Fukumura RKJ. Photodynamic therapy of cancer. Nat Rev Cancer 2003; 3: 380-7.

9. Waksman R, McEwan PE, Moore TI, Pakala R, Kologdie FD, Hellinga DG, Seabron RC, Rychnovsky SI, Vasek I, Scott RW, Virmani R. PhotoPoint photodynamic therapy promotes stabilization of atherosclerotic plaques and inhibits plaque progression. J Am Coll Cardiol 2008; 52: 1024-32.

10. Peng C, Li Y, Liang H, Cheng J, Li Q, Sun X, Li Z, Wang F, Guo Y, Tian Z, Yang L, Tian Y, Zhang Z, Cao W. Detection and photodynamic therapy of inflamed atherosclerotic plaques in the carotid artery of rabbits. J Photochem Photobiol B 2011; 102: 26-31.

11. Kossodo S, LaMuraglia GM. Kossodo S, LaMuraglia GM. Clinical potential of photodynamic therapy in cardiovascular disorders. Am J Cardiovasc Drugs 2001; $1: 15-21$.

12. Hsiang $\mathrm{Y}$, Stonefield M, Bower RD, Fragoso M, Tsang V, Crespo MT, Lundkvist A. Assessing Photofrin uptake in atherosclerosis with a fluorescent probe: comparison with photography and tissue measurements. Lasers Surg Med 1993; 13: 271-8.

13. Hsiang YN, Crespo MT, Richter AM, Jain AK, Fragoso M, Levy JG. In vitro and in vivo uptake of benzoporphyrin derivative into human and miniswine atherosclerotic plaque. Photochem Photobiol 1993; 57: 670-4.

14. Litvack F, Grundfest WS, Forrester JS, Fishbein MC, Swan HJ, Corday E, Rider DM, McDermid IS, Pacala TJ, Laudenslager JB. Effects of hematoporphyrin derivative and photodynamic therapy on atherosclerotic rabbits. Am J Cardiol 1985; 56: 667-71.

15. Kereiakes DJ, Szyniszewski AM, Wahr D, Herrmann HC, Simon DI, Rogers C, Kramer P, Shear W, Yeung AC, Shunk KA, Chou TM, Popma J, Fitzgerald P, Carroll TE, Forer D, Adelman DC. Phase I drug and light dose-escalation trial of motexafin lutetium and far red light activation (phototherapy) in subjects with coronary artery disease undergoing percutaneous coronary intervention and stent deployment: procedural and long-term results. Circulation 2003; 108 : 1310-5.

16. Liu Q, Hamblin MR. Macrophage-targeted photodynamic therapy: Scavenger receptor expression and activation state. Int J Immunopathol Pharmacol 2005; 18: 391-402.

17. McCarthy JR, Jaffer FA, Weissleder R. A macrophage-targeted theranostic nanoparticle for biomedical applications. Small 2006; 2: 983-7.

18. Tawakol A, Castano AP, Anatelli F, Bashian G, Stern J, Zahra T, Gad F, Chirico S, Ahmadi A, Fischman AJ, Muller JE, Hamblin MR. Photosensitizer delivery to vulnerable atherosclerotic plaque: comparison of macrophage-targeted conjugate versus free chlorin(e6). J Biomed Opt 2006; 11: 021008.

19. Kamat M, El-Boubbou K, Zhu DC, Lansdell T, Lu X, Li W, Huang X. Hyaluronic acid immobilized magnetic nanoparticles for active targeting and imaging of macrophages. Bioconjug Chem 2010; 21: 2128-35.

20. McCarthy JR, Korngold E, Weissleder R, Jaffer FA. A light-activated theranostic nanoagent for targeted macrophage ablation in inflammatory atherosclerosis. Small 2010; 6: 2041-49. 
21. Lovell JK, Liu TW, Chen J, Zheng G. Activatable photosensitizers for imaging and therapy. Chem Rev 2010; 110: 2839-57.

22. Choi $\mathrm{Y}$, Weissleder $\mathrm{R}$, Tung $\mathrm{CH}$. Selective antitumor effect of novel protease-mediated photodynamic agent. Cancer Res 2006; 66: 7225-9.

23. Jang B, Park JY, Tung CH, Kim IH, Choi Y. Gold nanorod-photosensitizer complex for near-infrared fluorescence imaging and photodynamic/ photothermal therapy in vivo. ACS Nano 2011; 5: 1086-94.

24. Bae BC, Na K. Self-quenching polysaccharide-based nanogels of pullulan/folate-photosensitizer conjugates for photodynamic therapy. Biomaterials 2010; 31: 6325-35.

25. Park W, Park SJ, Na K. The controlled photoactivity of nanoparticles derived from ionic interactions between a water soluble polymeric photosensitizer and polysaccharide quencher. Biomaterials 2011; 32: 8261-70.

26. Park SY, Baik HJ, Oh YT, Oh KT, Youn YS, Lee ES. A smart polysaccharide/drug conjugate for photodynamic therapy. Angew Chem Int Ed 2011; 50: 1644-7.

27. Yoon HY, Koo H, Choi KY, Lee SJ, Kim K, Kwon IC, Leary JF, Park K, Yuk SH, Park JH, Choi K. Tumor-targeting hyaluronic acid nanoparticles for photodynamic imaging and therapy. Biomaterials 2012; 33: 3980-9.

28. Jang B, Choi Y. Photosensitizer-conjugated gold nanorods for enzyme-activatable fluorescence imaging and photodynamic therapy. Theranostics 2012; 2: 190-7.

29. Cho Y, Choi Y. Graphene oxide-photosensitizer conjugate as a redox-responsive theranostic agent. Chem Commun 2012; 48: 9912-4.

30. Cho Y, Kim H, Choi Y. A graphene oxide-photosensitizer complex as an enzyme-activatable theranostic agent. Chem Commun 2013; 49: 1202-4

31. Shon SM, Choi Y, Kim JY, Lee DK, Park JY, Schellingerhout D, Kim DE. Photodynamic therapy using a protease-mediated theranostic agent reduces cathepsin-B activity in mouse atheromata in vivo. Arterioscler Thromb Vasc Biol 2013; 33: 1360-5.

32. Bogdan $\mathrm{C}$, Rollinghoff $\mathrm{M}$, Diefenbach A. Reactive oxygen and reactive nitrogen intermediates in innate and specific immunity. Curr Opin Immunol 2000; 12: $64-76$.

33. Kohr MJ, Roof SR, Zweier JL, Ziolo MT. Modulation of myocardial contraction by peroxynitrite. Front Physiol 2012; 3: 468.

34. Pennathur S, Bergt C, Shao B, Byun J, Kassim SY, Singh P, Green PS, McDonald TO, Brunzell J, Chait A, Oram JF, O'brien K, Geary RL, Heinecke JW. Human atherosclerotic intima and blood of patients with established coronary artery disease contain high density lipoprotein damaged by reactive nitrogen species. J Biol Chem 2004; 279: 42977-83.

35. Duan J, Kasper DL. Oxidative depolymerization of polysaccharides by reactive oxygen/nitrogen species. Glycobiology 2011; 21: 401-9.

36. Lee H, Lee K, Kim IK, Park TG. Fluorescent gold nanoprobe sensitive to intracellular reactive oxygen species. Adv Funct Mater 2009; 19: 1884-90.

37. Hamblin MR, Miller JL, Rizvi I. Pegylation of a chlorin(e6) polymer conjugate increases tumor targeting of photosensitizer. Cancer Res 2001; 61: 7155-62.

38. Soltes L, Mendichi R, Kogan G, Schiller J, Stankovska M, Amhold J. Degradative action of reactive oxygen species on hyaluronan. Biomacromolecules 2006; 7: 659-68.

39. Kennett EC, Davies MJ. Degradation of matrix glycosminoglycans by peroxynitrite/peroxynitrous acid: Evidence for a hydroxyl-radical-like mechanism. Free Radic Biol Med 2007; 42: 1278-89.

40. Li M, Rosenfeld L, Vilar RE, Cowman MK. Degradation of Hyaluronan by Peroxynitrite. Arch Biochem Biophys 1997; 341: 245-50.

41. Corsaro MM, Pietraforte D, Di Lorenzo AS, Minetti M, Marino G. Reaction of peroxynitrite with hyaluronan and related saccharides. Free Radic Res 2004; 38: 343-53.

42. Buttery LD, Sqringall DR, Chester AH, Evans TJ, Standfield EN, Parums DV, Yacoub MH, Polak JM. Inducible nitric oxide synthase is present within human atherosclerotic lesions and promotes the formation and activity of peroxynitrite. Lab Invest 1996; 75: 77-85.

43. Girish KS, Kemparaju K. The magic glue hyaluronan and its eraser hyaluronidase: a biological overview. Life Sci 2007; 80: 1921-43.

44. Bot PT, Pasterkamp G, Goumans MJ, Strijder C, Moll FL, de Vries JP, Pals ST, de Kleijn DP, Piek JJ, Hoefer IE. Hyaluronic acid metabolism is increased in unstable plaques. Eur J Clin Invest 2010; 40: 818-27. 